\title{
Assessment of potentially probiotic properties of Lactobacillus strains isolated from chickens
}

\author{
M. Kizerwetter-Świda, M. Binek \\ Department of Preclinical Sciences, Faculty of Veterinary Medicine, \\ Warsaw University of Life Sciences-SGGW, Ciszewskiego 8, 02-786 Warsaw, Poland
}

\begin{abstract}
This study was performed in order to isolate lactobacilli from chicken droppings and to select strains with the most promising probiotic properties. Lactobacillus strains were isolated from a flock of healthy laying hens. The first selection criterion was the ability to inhibit the growth of Salmonella Enteritidis. Then the tolerance to low $\mathrm{pH}$ and bile salt, the ability to coaggregate with pathogenic bacteria and hydrogen peroxide production were evaluated. Four isolates showing the best antagonistic activity against Salmonella Enetritidis were selected for further research. All isolates tested tolerated low $\mathrm{pH}$ and bile salt, likewise all produced hydrogen peroxide. They efficiently coaggregated with $C$. perfringens and relatively less with $E$. coli. Isolate $03^{\prime} 04$ displayed above-average results in all criteria, thus it is considered as a potential probiotic for chickens, and will be further evaluated for health promoting effect in animals. The results presented in this study confirm the strain specific probiotic properties and prove the probiotic potential of isolate $03^{\prime} 04$. Strong antagonistic properties against $C$. perfringens exhibited by certain Lactobacillus strains indicate the possibility to use them as a component of probiotic supplement in necrotic enteritis of poultry.
\end{abstract}

Key words: Lactobacillus, probiotic, chickens, coaggregation, E. coli, C. perfringens, Salmonella Enteritidis

\section{Introduction}

Probiotics have a number of beneficial health effects in the host intestinal microbiota (Saarela et al. 2000, Walter 2008). They have been commonly used in humans as well as in animal production. Presently, the popular approach is that probiotic bacterial strains should be individually tailored for each animal species because probiotic properties are strain specific (Ehrmann et al. 2002). Bacteria belonging to different lactic acid bacteria (LAB) are available as probiotic supplements, but lactobacilli are the most commonly used. Different properties contribute to the positive effects of probiotics on health, including interactions between intestinal bacteria and effects on the host. Beneficial effects are associated with production of lactic acid, acetic acid and other organic acids, hydrogen peroxide, competition for nutrients, ability to reduce adherence and colonization of pathogenic bacteria in gastrointestinal tract and production of inhibitory proteins called bacteriocins (Jin et al. 1996, Lima et al. 2007, Rehman et al. 2007, Walter 2008). Another mechanism by which probiotics exert their beneficial effect is the stimulation of the intestinal mucosal 
immune response and regulation of the inflammation processes by changing expression levels of the cytokines (Cao et al. 2012, Messaoudi et al. 2012b)

The search for a new probiotic strains is driven by the growing demand for reducing the antimicrobials use in food-production animals. There are many different probiotic products designated for chickens, however some of them may be not fully effective, most likely because of lack of the proper studies on the probiotic properties of bacterial strains included in these formulations. The selection criteria for a new probiotic strains include a series of in vitro and in vivo experiments. One of the desirable attribute is the ability of lactobacilli to coaggregate with pathogenic bacteria, which supports the activity of inhibitory agents secreted by lactobacilli (Ehrmann et al. 2002, Klaenhammer et al. 2008). Other important functional properties, which provide survival in the digestive system are the tolerance to gastric acid and bile salt (Garriga et al. 1998, Klaenhammer et al. 2008, Walter 2008).

This study was planned as a preliminary step for selection of potentially probiotic lactobacilli for further in vivo experiments. Hence, in this research Lactobacillus spp. were isolated from chicken GIT, isolates showing antagonistic activity against Salmonella Enetritidis were selected for further evaluation. Lactobacilli were investigated for low $\mathrm{pH}$ tolerance, bile salt tolerance, the ability to coaggregate with pathogenic bacteria and to produce hydrogen peroxide.

\section{Materials and Methods}

\section{Bacterial isolates and growth conditions}

Lactobacillus spp. have been isolated from fresh droppings of healthy laying hens (Withe Leghorn, 40 weeks of age) kept on litter. All birds were provided with free access to clean water and a standard feed. Bacteria were grown on De Man-Rogosa-Sharpe (MRS) agar (Oxoid) in anaerobic conditions at $37^{\circ} \mathrm{C}$ for $48 \mathrm{~h}$. The isolates were identified based on Gram's stain morphology, catalase reaction, and biochemical properties tested in API 50CHL (bioMerieux). Pathogenic bacteria: Escherichia coli, Salmonella Enteritidis and Clostridium perfringens have been isolated from chicken internal organs in the Microbiological Diagnostic Laboratory, Faculty of Veterinary Medicine, Warsaw Agriculture University.

\section{Agar spot test - detection of antibacterial activity}

Lactobacilli were tested for inhibitory activity against randomly selected clinical Salmonella Enter- itidis isolate. The agar spot test was performed according to the method described by Schillinger and Lucke (1989). Briefly, lactobacilli were spot inoculated on MRS agar and incubated at $37^{\circ} \mathrm{C}$ for 48 $\mathrm{h}$ in anaerobic conditions. Then, the plates were overlaid with $7 \mathrm{ml}$ of soft agar $\left(0.75 \%\right.$ agar) containing $10^{7}$ $\mathrm{CFU} / \mathrm{ml}$ of Salmonella Enteritidis and incubated aerobically at $37^{\circ} \mathrm{C}$ for $24 \mathrm{~h}$. The diameters of growth inhibition zones around lactobacilli were recorded.

\section{Acid and bile tolerance}

Acid and bile tolerance were examined according to the method described by Anderson et al. (2010) with some modifications. Each Lactobacillus isolate was grown overnight at $37^{\circ} \mathrm{C}$ in MRS broth. To determine acid tolerance the $\mathrm{pH}$ of each MRS broth was adjusted with $\mathrm{HCl}$ to 2.5 and then lactobacilli were incubated for $4 \mathrm{~h}$ at $37^{\circ} \mathrm{C}$ under anaerobic conditions. The number of viable cells was established using quantitative cultures on MRS agar before and after the incubation, in triplicate. Bile salts tolerance was verified by incubation of each isolate in MRS broth containing $0.5 \%(\mathrm{w} / \mathrm{v})$ of bile salt (Sigma). After $4 \mathrm{~h}$ of incubation at $37^{\circ} \mathrm{C}$ under anaerobic conditions, viable cells were counted as described above. The survival rate was calculated as $\log _{10}$ values of $\mathrm{CFU} / \mathrm{ml}$.

\section{Coaggregation experiments}

Coaggregation experiments were performed as described by Juárez Tomás et al. (2005). Overnight broth cultures of lactobacilli and pathogenic bacteria (E. coli, Salmonella Enteritidis or C. perfringens) were centrifuged, washed twice in coaggregation buffer of the following composition: $\mathrm{CaCl}_{2} 0.1 \mathrm{mM}, \mathrm{MgCl}_{2} 0.1$ $\mathrm{mM}, \mathrm{NaCl} 0.15 \mathrm{mM}, \mathrm{NaN}_{3} 3.1 \mathrm{mM}$ in $1 \mathrm{mM}$ Tris buffer, $\mathrm{pH}$ 7.0, and resuspended in this buffer. The volume of $2 \mathrm{ml}$ of each Lactobacillus suspension was mixed with $2 \mathrm{ml}$ of pathogenic bacteria and the $\mathrm{OD}_{600}$ was measured. After 2, 4, 12 and $24 \mathrm{~h}$ of incubation at room temperature, $\mathrm{OD}_{600}$ was measured again. The percent of coaggregation was calculated:

$$
\% \text { coaggregation }=\left(\mathrm{OD}_{1}-\mathrm{OD}_{2} / \mathrm{OD}_{1}\right) \times 100 \%
$$

Where $\mathrm{OD}_{1}$ is the initial optical density of mixture of Lactobacillus and pathogenic strain, $\mathrm{OD}_{2}$ is the optical density after $2 \mathrm{~h}, 4 \mathrm{~h}, 12 \mathrm{~h}$, and $24 \mathrm{~h}$ of incubation. 
Table 1. The tolerance of isolated lactobacilli to low $\mathrm{pH}$ and bile salt.

\begin{tabular}{cccccc}
\hline \multirow{2}{*}{ Isolates } & \multirow{2}{*}{$\begin{array}{c}\text { Initial } \log _{10} \\
\text { CFU/ml* }\end{array}$} & \multicolumn{2}{c}{$\mathrm{pH} 2.5$} & \multicolumn{2}{c}{$0.5 \%$ of bile salt } \\
\cline { 3 - 6 } & $\log _{10}$ CFU/ml after 4 h & $\%$ of viability & $\log _{10}$ CFU/ml after 4 h & $\%$ of viability \\
\hline $03 ' 04$ & $8.10 \pm 0.09$ & $7.89 \pm 0.11$ & $97 \%$ & $7.65 \pm 0.19$ & $94 \%$ \\
$01^{\prime} 05$ & $7.69 \pm 0.12$ & $7.30 \pm 0.17$ & $95 \%$ & $7.04 \pm 0.21$ & $92 \%$ \\
$03^{\prime} 05$ & $8.42 \pm 0.37$ & $7.97 \pm 0.21$ & $95 \%$ & $7.43 \pm 0.24$ & $88 \%$ \\
$10^{\prime} 05$ & $8.08 \pm 0.19$ & $7.63 \pm 0.18$ & $94 \%$ & $7.41 \pm 0.18$ & $92 \%$ \\
\hline
\end{tabular}

* - Values are the mean $\pm \mathrm{SD}$ from three independent experiments

\section{Determination of hydrogen peroxide production}

Lactobacillus isolates were tested for hydrogen peroxide production $\left(\mathrm{H}_{2} \mathrm{O}_{2}\right)$ by the qualitative plate method, using horseradish peroxide incorporated in 3,3',5,5'-tetramethylbenzidine (TMB, Sigma) MRS agar medium (Eschenbach et al. 1989). Lactobacilli were cultured on MRS agar containing $1 \mathrm{mM}$ TMB and $2 \mathrm{U} / \mathrm{ml}$ horseradish peroxide (Sigma). Plates were incubated in anaerobic conditions at $37^{\circ} \mathrm{C}$ for $48 \mathrm{~h}$. Colonies of $\mathrm{H}_{2} \mathrm{O}_{2}$-producing strains turned blue after exposure to air for $30 \mathrm{~min}$.

\section{Results}

In total 62 isolates were obtained from chicken droppings. All these bacteria were presumptively identified as lactobacilli, because of the ability to grow on MRS agar, Gram positive, rod shape cell morphology and the negative results in catalase test. Four isolates showing the widest inhibition zones $10 \mathrm{~mm}$ (isolate designated as $\left.1^{\prime} 05\right), 11 \mathrm{~mm}\left(10^{\prime} 05\right), 14 \mathrm{~mm}$ $\left(03^{\prime} 04\right)$, and $15 \mathrm{~mm}\left(3^{\prime} 05\right)$ obtained in agar spot test with Salmonella Enetritidis were selected for further evaluations. These isolates, in accordance to API50CH, were identified as L. salivarius $\left(03^{\prime} 04\right.$, $01^{\prime} 05$ and $\left.10^{\prime} 05\right)$ and L. brevis (03'05).

The results of acid and bile tolerance are shown in Table 1. All isolates were able to tolerate $\mathrm{pH} 2.5$ with the loss of viability from $97 \%$ to $94 \%$. Slightly lower tolerance was observed to $0.5 \%$ of bile salt, however the loss of viability was within a range from $94 \%$ to $88 \%$. The isolate 03 '04 has showed a clearly greater resistance to low $\mathrm{pH}$ and bile salt.

Figures 1-3 present the results of coaggregation of evaluated Lactobacillus isolates with pathogenic bacteria. In general, all Lactobacillus isolates shown higher ability to coaggregate with $C$. perfringens comparing to other pathogens. The percentage of coaggregation with $C$. perfringens observed after 24 hours for isolate $03^{\prime} 04$ was $71 \%$, and from $43 \%$ to $52 \%$ for the remaining three isolates. The percentage of coaggregation with E. coli and Salmonella displayed by isolate $03^{\prime} 04$ was $37 \%$ and $53 \%$ respectively. These values for the other isolates ranged from $17 \%$ to $23 \%$ for $E$. coli and from $12 \%$ to $21 \%$ for Salmonella.

All Lactobacillus isolates tested has been classified as hydrogen peroxide producers, as confirmed by observing the dark blue colonies after exposure to air.

\section{Discussion}

In 2002 the FAO/WHO Working Group developed new guidelines for the introduction of a new probiotics microorganisms. The special attention was put on safety assessment and effectiveness. The guidelines contain the following recommendations: in vitro tests to evaluate probiotic potential and in vivo clinical on animals or humans (FAO/WHO, 2002). The use of in vitro test as selection criteria is unavoidable and contributes to reducing the number of strains for in vivo testing (Taheri et al. 2009). The isolation of various Lactobacillus species including $L$. salivarius and $L$. brevis from chicken GIT has been reported previously, which is in line with identification of isolates described in the present study (Kizerwetter-Świda and Binek 2009, Bujnakova et al. 2014).

One of the crucial properties of probiotic lactobacilli is the ability to survive in the low $\mathrm{pH}$ of the stomach and in the high concentration of bile salt of the upper GIT. The capability to tolerate acid and bile is considered as good indicators for the viability in the GIT, thus these characteristics are often assessed in preliminary examination of potentially probiotic strains (Bull et al. 2013).

In our experiment four Lactobacillus isolates showing the best ability to inhibit the growth of Salmonella Enteritidis, were selected for further evaluations. Isolate $03^{\prime} 04$ showed significantly higher tolerance to low $\mathrm{pH}$ and bile salt, with the viability $97 \%$ at $\mathrm{pH} 2.5$ and $94 \%$ in $0.5 \%$ of bile salt. However, all other isolates showed good tolerance to these conditions and their viability ranged from $94 \%$ to $95 \%$ in low $\mathrm{pH}$, and from $88 \%$ to 92 in bile salt. Obtained 


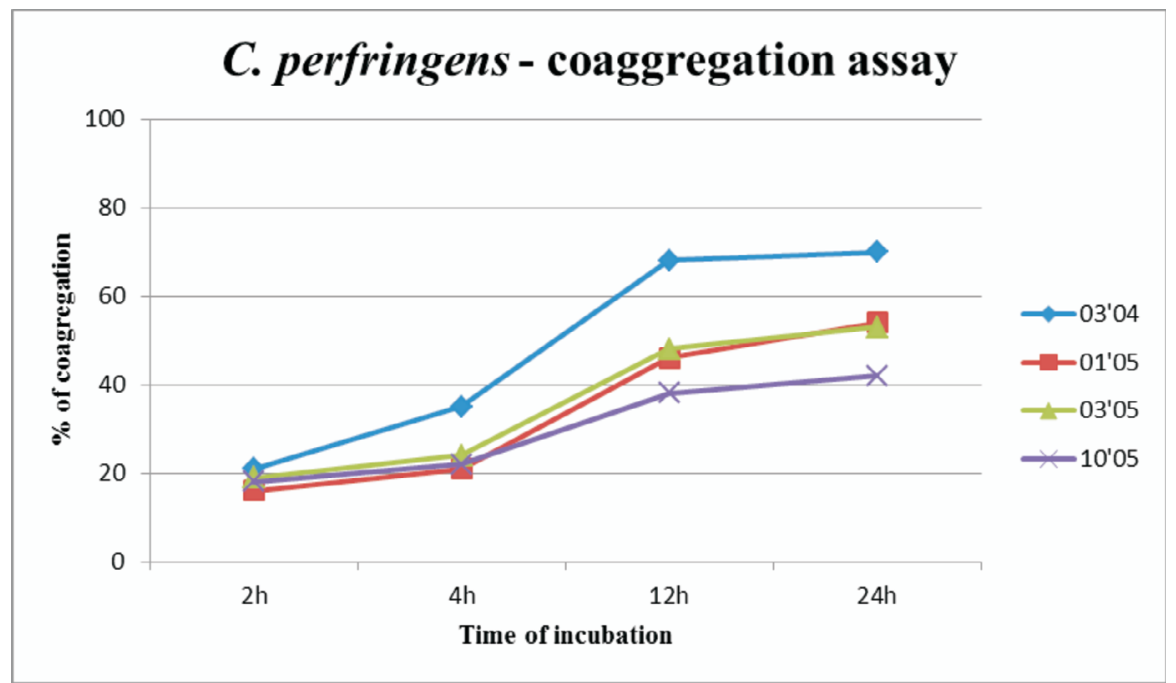

Fig. 1. Coaggregation ability of Lactobacillus isolates with C. perfringens.

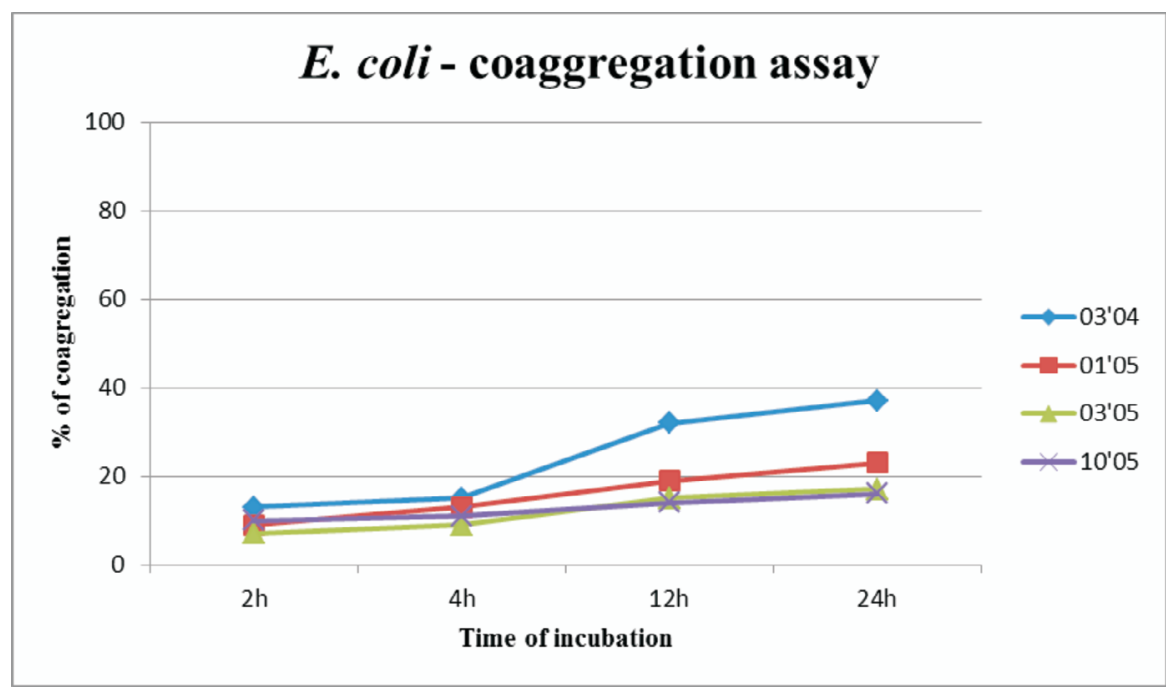

Fig. 2. Coaggregation ability of Lactobacillus isolates with E. coli.

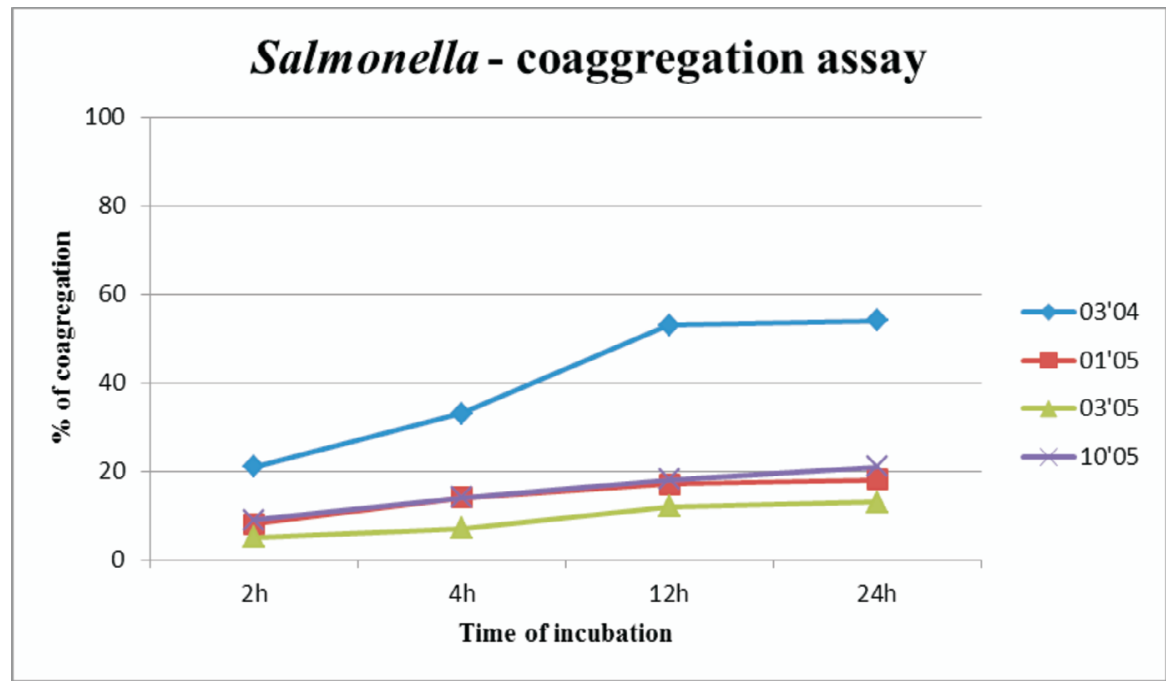

Fig. 3. Coaggregation ability of Lactobacillus isolates with Salmonella spp. 
results confirm that the acid and bile tolerance is specific only for some Lactobacillus isolates (Ehrmann et al. 2002, Taheri at al. 2009). Survival of different lactobacilli was dependent on the time and the $\mathrm{pH}$ or bile salts concentration used in individual studies. Some isolates of chicken origin exhibited even $100 \%$ survival rate at $\mathrm{pH}$ of 2.0 , while others showed no viability at those conditions (Garriaga et al. 1998, Lee et al. 2008, Bujnakova et al. 2014). Hashemi et al. (2014) described significantly lower viability of lactobacilli after $2 \mathrm{~h}$ of incubation at the $\mathrm{pH} 2$ or in $0.3 \%$ of bile salt, but all evaluated bacteria were obtained from traditional kurdish cheese. It is well documented that lactobacilli isolated from GIT are able to tolerate low $\mathrm{pH}$ and bile salt, as compared to strains obtained from fermented food products (Ehrmann et al. 2002, Koll et al. 2008). The greater bile tolerance of particular Lactobacillus strains was proved to be correlated with the presence of bile salt hydrolases genes in their cells (Klaenhammer et al. 2008, Messaoudi et al. 2012b).

Coaggregation of lactobacilli with enteropathogenic bacteria is well known and has previously been reported by various authors (Garriga et al. 1998, Taheri et al. 2009). Ability to coaggregate is also a property specific to the particular genus and species. Strain specific, selective in vitro activity of probiotic lactobacilli against $C$. perfringes was described previously (Kizerwetter-Świda and Binek 2005). Other studies such as that of Valeriano et al. (2014) reported high coaggregation ability of lactobacilli isolated from piglet feaces with E. coli and Salmonella. It is remarkable, that some Lactobacillus strains demonstrate extremely wide range of antagonistic activity including also Campylobacter jejuni, C. coli, and also Listeria spp., and Staphylococcus aureus (Messaoudi et al. 2012a). The presented study showed that isolate $03^{\prime} 04$ exhibited the highest coaggregation abilities, particularly with $C$. perfringens, as compared to the remaining three isolates.

Hydrogen peroxide is one of the metabolites that may be produced by Lactobacillus and other lactic acid bacteria (LAB) and may contribute to the inhibition of pathogenic bacteria. The quantity of $\mathrm{H}_{2} \mathrm{O}_{2}$ produced by different $\mathrm{LAB}$ varies, depending on the strain, and for some of them $\mathrm{H}_{2} \mathrm{O}_{2}$ production is not observed (Sabir et al. 2010). All four isolates tested in our study showed the ability to produce $\mathrm{H}_{2} \mathrm{O}_{2}$, which may promote their antagonistic activity against pathogenic bacteria.

All four evaluated Lactobacillus isolates were able to tolerate low $\mathrm{pH}$ and bile salt, showed good coaggregation scores with pathogenic bacteria and produce $\mathrm{H}_{2} \mathrm{O}_{2}$ production, thus they could be considered as a components of probiotics supplement for poultry.
Isolate $03^{\prime} 04$ showing above-average results in all investigated attributes seems particularly promising candidate for in vivo experiments. These results strongly suggest the desirability of in vitro assessment of a new potentially probiotic bacteria, what is expected to contribute to the development of more effective probiotic supplements for poultry.

\section{Acknowledgments}

This work was supported by the Ministry of Science and Higher Education (grant No. N30801132/1242).

\section{References}

Anderson RC, Cookson AL., McNabb WC, Kelly WJ, Roy NC (2010) Lactobacillus plantarum DSM 2648 is a potential probiotic that enhances intestinal barrier function. FEMS Microbiol Lett 309: 184-192.

Bujnakova D, Strakova E, Kmet V (2014) In vitro evaluation of the safety and probiotic properties of lactobacilli isolated from chicken and calves. Anaerobe 29: 118-127.

Bull M, Plummer S, Marchesi J, Mahenthiralingam E (2013) The life history of Lactobacillus acidophilus as a probiotic: a tale of revisionary taxonomy, misidentification and commercial success. FEMS Microbiol Lett 349: 77-87.

Cao L, Yang XJ, Li ZJ, Sun FF, Wu XH, Yao JH (2012) Reduced lesions in chickens with Clostridium perfringens-induced necrotic enteritis by Lactobacillus fermentum 1.20291. Poult Sci 91: 3065-3071.

Ehrmann MA, Kurzak P, Bauer J, Vogel RF (2002) Characterization of lactobacilli towards their use as probiotic adjuncts in poultry. J Appl Microbiol 92: 966-975.

Eschenbach DA, Davick PR, Williams BL, Klebanoff SJ, Young-Smith K, Critchlow CM, Holmes KK (1989) Prevalence of hydrogen peroxide-producing Lactobacillus species in normal women and women with bacterial vaginosis. J Clin Microbiol 27: 251-256.

FAO/WHO (2002) Joint FAO/WHO Working group report on drafting guidelines for the evaluation of probiotics in food. London, Ontario, Canada, pp 1-11.

Garriga M, Pascual M, Monfort JM, Hugas M (1998) Selection of lactobacilli for chicken probiotic adjuncts. J Appl Microbiol 84: 125-132.

Hashemi SM, Shahidi F, Mortazavi SA, Milani E, Eshaghi Z (2014) Potentially probiotic Lactobacillus strains from traditional Kurdish cheese. Probiotics Antimicrob Proteins 6: 22-31.

Jin LZ, Ho YW, Abdullah N, Ali MA, Jalaludin S (1996) Antagonistic effects of intestinal Lactobacillus isolates on pathogens of chicken. Lett Appl Microbiol 23: 67-71.

Juárez Tomás MS, Wiese B, Nader-Macías ME (2005) Effects of culture conditions on the growth and auto-aggregation ability of vaginal Lactobacillus johnsonii CRL 1294. J Appl Microbiol 99: 1383-1391.

Kizerwetter-Swida M, Binek M (2009) Protective effect of potentially probiotic Lactobacillus strain on infection 
with pathogenic bacteria in chickens. Pol $\mathrm{J}$ Vet Sci 12: $15-20$.

Kizerwetter-Świda M, Binek M (2005) Selection of potentially probiotic Lactobacillus strains towards their inhibitory activity against poultry enteropathogenic bacteria. Pol J Microbiol 54: 287-294.

Klaenhammer TR, Altermann E, Pfeiler E, Buck BL, Goh YJ, O'Flaherty S, Barrangou R, Duong T (2008) Functional genomics of probiotic Lactobacilli. J Clin Gastroenterol 42 (Suppl 3): S160-S162.

Kõll P, Mandar R, Marcotte H, Leibur E, Mikelsaar M, Hammarström L (2008) Characterization of oral lactobacilli as potential probiotics for oral health. Oral Microbiol Immunol 23: 139-147.

Lee NK, Yun CW, Kim SW, Chang HI, Kang CW, Paik HD (2008) Screening of Lactobacilli derived from chicken feces and partial characterization of Lactobacillus acidophilus $\mathrm{A} 12$ as an animal probiotics. J Microbiol Biotechnol 18: 338-342.

Lima ET, Andreatti Filho RL, Okamoto AS, Noujaim JC, Barros MR, Crocci AJ (2007) Evaluation in vitro of the antagonistic substances produced by Lactobacillus spp. isolated from chickens. Can J Vet Res 71: 103-107.

Messaoudi S, Kergourlay G, Dalgalarrondo M, Choiset Y, Ferchichi M, Prévost H, Pilet MF, Chobert JM, Manai M, Dousset X (2012a) Purification and characterization of a new bacteriocin active against Campylobacter produced by Lactobacillus salivarius SMXD51. Food Microbiol 32: 129-134.
Messaoudi S, Madi A, Prevost H, Feuilloley M, Manai M, Dousset X, Connil N (2012b) In vitro evaluation of the probiotic potential of Lactobacillus salivarius SMXD51. Anaerobe 18: 584-589.

Rehman HU, Vahjen W, Awad WA, Zentek J (2007) Indigenous bacteria and bacterial metabolic products in the gastrointestinal tract of broiler chickens. Arch Anim Nutr 61: 319-335.

Saarela M, Mogensen G, Fonden R, Matto J, Mattila-Sandholm T (2000) Probiotic bacteria: safety, functional and technological properties. J Biotechnol 84: 197-215.

Sabir F, Beyatli Y, Cokmus C, Onal-Darilmaz D (2010) Assessment of potential probiotic properties of Lactobacillus spp., Lactococcus spp., and Pediococcus spp. strains isolated from kefir. J Food Sci 75: M568-M573.

Schillinger U, Lücke FK (1989) Antibacterial activity of Lactobacillus sake isolated from meat. Appl Environ Microbiol 55: 1901-1906.

Taheri HR, Moravej H, Tabandeh F, Zaghari M, Shivazad M (2009) Screening of lactic acid bacteria toward their selection as a source of chicken probiotic. Poult Sci 88: 1586-1593.

Valeriano VD, Parungao-Balolong MM, Kang DK (2014) In vitro evaluation of the mucin-adhesion ability and probiotic potential of Lactobacillus mucosae LM1. J Appl Microbiol. 117: 485-497.

Walter $\mathbf{J}$ (2008) Ecological role of lactobacilli in the gastrointestinal tract: implications for fundamental and biomedical research. Appl Environ Microbiol 74: 4985-4996. 